\title{
Cost analysis of neonates after prenatal corticosteroid prophylaxis of Respiratory Distress Syndrome
}

\author{
Anna Mihaylova ${ }^{1}$, Petya Kasnakova ${ }^{1}$, Stanislav Gueorguiev ${ }^{2}$, Elina Petkova-Gueorguieva ${ }^{2}$, \\ Lili Peykova ${ }^{3}$ \\ 1120 Br. Bukstone str., Medical College, Medical University of Plovdiv, Bulgaria \\ 2 Department of Pharmaceutical Sciences, Faculty of Pharmacy, Medical University of Plovdiv, Bulgaria \\ 3 Department of Pharmaceutical chemistry, Faculty of Pharmacy, Medical University Sofia \\ Corresponding author: Lili Peykova ( lily_peikova@yahoo.com)
}

Received 24 January 2020 • Accepted 25 March 2020 • Published 2 October 2020

Citation: Mihaylova A, Kasnakova P, Gueorguiev S, Petkova-Gueorguieva E, Peykova L (2020) Cost analysis of neonates after prenatal corticosteroid prophylaxis of Respiratory Distress Syndrome. Pharmacia 67(4): 209-214. https://doi.org/10.3897/pharmacia.67.e50458

\begin{abstract}
Preterm birth is a vital global health-economic problem. Health disorders provoked by it generate a high neonatal mortality rate. Prenatal corticosteroid prevention aims to reduce postnatal complications in premature infants. This survey covered two basic baby groups: work group of 89 premature infants that had been subjected to prenatal corticosteroid prophylaxis and a control group of 78 premature babies without prenatal prevention. The analysis of the pharmacoeconomic aspects of prenatal corticosteroid prevention enabled the comparison of clinical and therapeutic results, treatment costs, therapeutic expenditures, shortterm therapeutic effect, benefits and sequences from premature infants' therapy. The analysis of clinical data obtained during this survey enabled the conclusion that when analyzing the combined effect of Dexamethasone prophylaxis, gestation week at birth and the age of the mother of premature infants with RDS, respiratory obstuction occurrence was mediated by the earlier gestation week at birth, older mother's age and, at this background, it was restricted to a certain extent by prenatal corticosteroid administration. Conclusions: Prenatal corticosteroids cause reduction of premature infants' treatment costs. The implementation of a smaller number of dexamethasone applications leads to smaller expenditures for premature infants' treatment and care compared to those that have more dexamethasone applications.
\end{abstract}

\section{Keywords}

preterm birth, prenatal corticosteroid prophylaxis, health costs, premature neonates, RDS

\section{Introduction}

Preterm birth is a significant current public health problem. It is the most frequent cause for neonatal death in developed countries (Blencowe et al. 2012, Goldenberg et al. 2008, Heaman et al. 2005, Heron 2012), represents 80\% of all neonatal death incidence rate in the world (more than 1.1 million) (Howson et al. 2012, Steer 2005) and more than $30 \%$ of that in Europe (Euro-Peristat 2010). By 2010 in the USA more that $12 \%$ of all births were preterm marking a 30\% increase in the period since 1981 (Hamilton et al. 2011, Martin et al.2012). In Brazil, the rate is about $6.5 \%$ in 2006, with an increase reaching up to 10.7\% in 2011 (Brazilian Ministry of Health 2013)

The Bulgarian statistics produced data that $10-12 \%$ (2015) of all pregnancies terminated with a preterm birth. 
In spite of the series of surveys in this field and the efforts of specialists in Gynecology and Obstetrics preterm births follow a continuous trend to increasing (Sandeva and Uchikova 2016)

The effects of preterm birth involve a number of medico-biological and socioeconomic negatives. The studies of Petrou S. et al analyzed the complex of negative aspects of preterm birth during the first 5 and further during the 10 years of life of preterm infants (Petrou et al. 2003, Petrou et al. 2001, Petrou 2005). The authors generalized that cerebral paralysis marked a greater incidence rate in premature infants than in babies born on term. The first group evidenced more frequently permanent complications following developed respiratory diseases and sensory deficiencies. The higher morbidity rate associated with preterm birth affected the individual in older age as well. This caused substantial physical disorders of various degree, emotionally-psychological negative sequences and significant socioeconomic costs for the family and for the public as a whole. Adequate, specialized prenatal care is extremely important in the reduction of preterm births rate. They have to be individually mediated taking into consideration the complex of risk predispositions for each particular pregnancy case (Iams et al. 2008, Krueger and Scholl 2000).

Approximately 15 millions of premature infants are born each year in the world (Preterm Labor and Birth: Condition Information“ 2015). One of the pathological syndromes of preterm babies is associated with the lung development and is known as neonatal Respiratory Distress Syndrome (nRDS). It is caused by a deficient surfactant synthesis combined with structural immaturity of the lungs. It is also possible that it is an outcome of neonatal infection (Chan et al. 2013, Sinha 2012). Respiratory distress syndrome affects $1 \%$ of the premature infants globally and is the main death cause for this group of patients (Rodriguez et al. 2002). The clinical manifestation of hyaline membrane disease occurs either immediately after birth or up to 6 hours after it. The signs observed in a newborn with RDS are: tachypnea - abnormally rapid breathing, expiratory moan, epigastric and intercostal circulation, nostril breathing, cyanosis - appearance of bluish or livid color on the skin and mucosa, due to the fact that the tissues situated near the skin surface receive lower oxygen saturation (Mitchell et al. 2014, Moore and Persaud 2002), occurrence of apnea and/or hypothermia is possible (Ballard et al. 2006). Hyaline membrane disease often causes additional complications. They are classified mainly in two groups - early (acute) and distant (chronic) effects. The acute ones include: lung edema, infection, intracranial hemorrhage and periventricular leukomalacia, apnea, lung hemorrhage, necrotizing enter colitis and/or gastrointestinal perforation. The chronic aggravations are: bronchopulmonary dysplasia, retinopathy, neurological disorders (Fanaroff et al. 2007).

Prenatal and neonatal practice implement more and more recent and adaptive prophylaxis of preterm birth focused on reduction of death risk of preterm newborns; minimizing the possibility of development of healthy complications in the newborns of mothers who have been subjected to therapy. All countries in the world, developed or developing, outline common strive to achieve optimal resolution of the issues associated with premature newborns and their families.

Preterm birth prophylaxis between 22 and 35 gestation week involves measuring the length of the uterine cervix, Doppler scan for evaluation of the blood circulation in a cascade of mother's and fetal blood vessels, fetal fibronectin test, hospitalization, implementation of tocolytic therapy, administration of corticosteroids to achieve maximal fetus maturity.

Glucocorticoids are implemented in medical practice when there is a possible risk for preterm birth aiming to provide sufficient time to the fetus to develop its lungs to the necessary stage. They also help in reducing RDS incidence rate, as well as the rate of ventricular hemorrhages in preterm newborns, in reduction of neonatal morbidity and mortality rate by about 50\% (Danesh et al. 2012).

The efficacy of prenatal steroid therapy depends mostly on the gestation age. Mori $\mathrm{R}$ et al in their survey evaluated the effectiveness of this treatment among 11067 newborns of gestation age between $22^{\text {nd }}$ and $33^{\text {rd }}$ week. The found results outlined the conclusion that prenatal steroids helped in the reduction of the respiratory distress syndrome risk occurrence by $9 \%$. The conclusion that the treatment effectiveness is greater in newborns in the $24^{\text {th }}-29^{\text {th }}$ gestation week as the respiratory distress syndrome risk is decreased by $20 \%$ is of greater significance (Mori et al. 2011).

There is evidence that the incomplete treatment course with Betamethasone or Dexamethasone created certain advantages from the viewpoint of reducing the morbidity rate among preterm newborns. Those advantages were possibly due to administration of inadequate drug doses or a shorter treatment course when the fetus was less exposed to steroid effect (Elimian et al. 2003).

According to British physicians' recommendations the prenatal steroid treatment can be repeated before $34^{\text {th }}$ gestation week if the first therapy course was terminated 7 days before the $26^{\text {th }}$ gestation week (Royal College of Obstetricians and Gynaecologists 2010). Crowther et al generalized the results of 8 surveys associated with repeated steroid course after a 7-day interval. Based on the available evidence a conclusion was formulated that the respiratory distress syndrome occurred less frequently among newborns subjected to repeated therapy $(\mathrm{OR}=0.83$ (95\% CI 0.75-0.91)) (Crowther et al. 2011). Some researchers supposed that the administration of more than two corticosteroid treatment courses could have more serious effects on the newborn development. French NP et al proved that the serial steroid courses applied between $24^{\text {th }}$ and $33^{\text {rd }}$ gestation week reduced the birth weight as well as the circumference of the head (French at al. 1999).

Chien et al published data for prenatal steroid therapy of 11440 newborns. In this survey only 30\% of the newborns underwent the complete therapeutic course. The evidence revealed that just those $30 \%$ demonstrated 
substantial reduction of the possibility to develop respiratory distress syndrome but only in case they were born between $24^{\text {th }}$ and $34^{\text {th }}$ gestation week. Those newborns with incomplete treatment course did not show significant differences in the chance to develop respiratory distress syndrome compared to those who were administered the complete course (Chien et al. 2002).

The effective corticosteroid prophylaxis aims at mitigation of postnatal complications in preterm infants and reduction of their stay at neonatal and intensive units, leading to serious socioeconomic problems.

The application of prenatal corticosteroids reduces the total health care costs. According to the publication of Crowley P. the risks for periventricular hemorrhage as well as for necrotizing enter colitis are reduced among newborns with prenatal corticosteroid prophylaxis (Crowley 1995). The author stated that the surveys had not detected long term negative effects in the development of newborns with corticosteroid prophylaxis. The reduction of the neonatal care costs for surviving newborns outweighed the relatively low treatment costs, treatment implementation and mother's control, thus making the implementation of prenatal corticosteroids economically profitable health prevention.

The use of prenatal corticosteroids can lead to net savings in the cost of saving lives for newborns before 31 gestational age and weighing less than $2000 \mathrm{~g}$ (Carmichael and Abrams 1997) (Chaikind and Corman 1991). In 1991, Mugford M. estimated cost reductions in prenatal corticosteroids in selected patients based on the cost of care for newborns with and without respiratory distress. Mugford $\mathrm{M}$ estimated that prescribing prenatal corticosteroids to expectant mothers who were 35 years pregnant would reduce the average cost of having a newborn by $10 \%$, lowering the average cost of surviving a newborn by $14 \%$ (Chaikind and Corman 1991). However, if prenatal corticosteroids were prescribed only to expectant mothers, before 31 gest. week of pregnancy, prenatal corticosteroid prescribing would increase overall consumption by $7 \%$ and reduce the cost of surviving a newborn by $9 \%$.

In a study conducted in 1970s, Liggins G. and Howie $\mathrm{R}$. found that if pregnant women at risk of preterm birth were prescribed corticosteroids, their infants' chances of developing respiratory distress syndrome were significantly reduced. The applications they place are betamethasone phosphate or betamethasone acetate. This study, as well as based on its findings, change the treatment used by physicians in the case of an existing risk of childbirth between 24 and 36 gest. age in order to improve the quality of life of premature infants (Chander P. et al. 2015)

The pharmacoeconomic analysis of the corticosteroid prophylaxis enable the comparison of therapeutic results, treatment costs, short term therapeutic effect, benefits and effects of the therapy of prematurely born infants with HMD and other forms of respiratory distress syndrome. The early pharmacoeconomic models depend on the available technologies, healthcare expenditures and drug costs.
The formulation of answers and solutions for the existing issues associated with the prevention and treatment of RDS would lead to reduced risk for neonatal morbidity and to prevention or mitigation of the appearance and development of additional RDS concomitant complications, respectively improved newborn's life quality. From the viewpoint of pharmacoeconomics it would bring net savings in the expenditures for saved newborn life which is related to reduction of the direct costs for drug therapy and reduction of the overall healthcare expenses.

\section{Aim}

The aim of this study is to make a pharmacoeconomic analysis of prenatal corticosteroid prophylaxis of Respiratory Distress Syndrome in prenatal newborns, evaluating the costs incurred for their treatment.

\section{Materials and methods}

The Clinic of Gynecology and Obstetrics at the University Hospital for Acute Treatment "St. George" - Plovdiv conducted a retrospective and prospective survey covering one and a half year period. Two groups of newborns were formed based on conducted or not conducted prenatal corticosteroid therapy. The infants whose mothers were administered a prophylactic corticosteroid course were recognized as "cases" or work group and those without prenatal prophylaxis were "controls" or control group. The documentary method is mainly used, with primary data on preterm infants being collected from next documents "Case History“, „Newborn History“, „Birth History“, „Epicrisis of the Mother“ and „Epicrisis of the Newborn Baby“.

The survey covered 167 preterm infants. They were divided into two basic groups: "cases" or workgroup of 89 prematurely born infants with applied corticosteroid prophylaxis and a second group - "controls", consisting of 78 preterm infants without prenatal prophylaxis.

The subject of observation is the differences between: health complications (presence or absence of HMD, RDS, other complications, clinical and laboratory results, etc.), social characteristics and pharmacoeconomic therapeutic aspects of preterm infants with the presence or absence of prenatal corticosteroid prophylaxis. hyaline-membrane disease.

Case of observation: is the available medical records (clinical data) of each premature infant who meet the criteria for inclusion in the study.

Indicators analyzed: characteristics of dexamethasone prophylaxis, presence or absence of hyaline-membrane disease, health status and additional complication of premature infants, maternal health and gynecological status, pharmaco-economic indicators of diagnostic and therapeutic activities as premature infants, and mothers, a detailed pharmacoeconomic analysis of RDS etc. 
Also used are: Statistical methods, the results are processed with the SPSS statistical package, Ver. 19 and are statistically significant at the significance level $\alpha=0.05$. Questionnaire survey by completing an individual report. Cost analysis - the method is used to evaluate the spent health resources that are related to the value of the clinical pathways used to treat premature infants. The total costs in the workgroup and control group are calculated as the sum of the price and the amount of resource used, using the formula: Total cost $=\sum$ (Q quantity $\mathrm{x} \mathrm{p}$ price). The working group of 89 premature babies was divided into 45 babies with full course of Corticosteroid prevention by two or three dexamethasone applications - 2 applications amp. $6 \mathrm{mg} / \mathrm{ml}$, a total of $12 \mathrm{mg}$. or 3 applications amp. $4 \mathrm{mg} / \mathrm{ml}$, a total of $12 \mathrm{mg}$. and $43 \mathrm{ba}$ bies with incomplete Corticosteroid prevention with one dexamethasone $4 \mathrm{mg} / \mathrm{ml}$ application.

We examined the two main groups - infants whose mothers were subjected to prenatal prophylactic corticosteroid course (cases) and the workgroup - those without prenatal prophylaxis (controls) or control group.

The obtained data were statistically processed by correlation analysis (Pearson, Spearman coefficient), frequency distribution, linear regression analysis, nonparametric dispersion analysis (Mann-Whitney Test), and Chi-square using the SPSS software version 19.0.

\section{Results and discussion}

Prenatal corticosteroid prophylaxis implemented on the mothers of the studied infants included the synthetic glucocorticosteroid Dexamethasone $4 \mathrm{mg} / \mathrm{ml}$ solution for injection of Krka company, at the cost of 0.44 BGN per ampoule. All preterm infants covered by the study were preventively treated with Dexamethasone, but, if there had been infants treated with Betamethasone we would be able to make the analysis "cost - minimum" and to compare the undesired drug reactions to the two corticosteroids. For the aim of this survey we used the pharmacoeconomic methods "cost analysis" and "cost-effectiveness".

Prenatal corticosteroids are covered by the algorithm of Clinical Path 1 (CP1) Stationary care for high-risk pregnancy, Clinical Path 2 (CP2) Prenatal invasive pregnancy diagnostics and intensive care for pregnancy with realized risk and Clinical Path 3 (CP3) Birth. The costs of those clinical paths reimbursed by the National Health Insurance Fund (NHIF) are respectively: CP1 - 390 BGN, CP - $800 \mathrm{BGN}$ and CP3 - $580 \mathrm{BGN}$.

The discussion of the clinical data from the present survey enabled us to formulate the conclusion that when analyzing the combined effect of Dexamethasone prophylaxis, gestation week at birth and the mother's age of preterm newborns with HMD, the occurrence of HMD was mediated by the earlier gestation week at birth, older mother's age and at this background it was to a certain extent restricted by prenatal application of corticosteroids. In this pharmacoeconomic survey we analyzed whether that thesis would be confirmed also by reduction of expenses allocated for the newborns with prenatal corticosteroid prophylaxis.

The costs for 167 preterm born infants hospitalized at the medical institution by a total of 20 clinical paths paid by NHIF according to National Framework Agreement 2015 and National Framework Agreement 2016 amounted to $514855 \mathrm{BGN}$. Those clinical paths were paid by NHIF to the hospital amounting from 160 BGN to 5600 BGN per clinical path. The infants were hospitalized for a minimum of one $\mathrm{CP}$ and some of them were admitted for a second, third, fourth, and fifth clinical path consecutively. The lowest cost of a CP is 160 BGN and a total of 12 infants were admitted for this CP; the highest cost for five sequential CPs (2 infants) was 13822 BGN. The "case" group consisted of 89 infants and the CP expenses for them were 245827 BGN (average cost per infant $-2762 \mathrm{BGN}$ ). The second group, the control one consisted of 72 infants without prenatal corticosteroid prophylaxis. The CP expenditures for them were 269082 BGN (average expense per infant - 3737 BGN. Those numbers showed a difference of approximately 1000 BGN per infant, in favor of infants with prophylaxis. (Tab.1)

We could generalize that each infant with prenatal corticosteroid prophylaxis was allocated an expenditure that was as an average by 1000 BGN lower than that paid for children without corticosteroid prophylaxis. This conclusion supports the thesis that prenatal corticosteroids besides mitigating the complications in preterm born infants, cause also reduction of the costs for their treatment.

An additional internal re-grouping on the basis of some indicators was performed for the aims of the survey: complete, incomplete or lack of preventive corticosteroid course.

The analysis of the clinical data showed that the single prenatal application of Dexamethasone (defined as short-term prophylactic course) had a better preventive

Table 1. Expenditures by CP for infants with and without corticosteroid course.

\begin{tabular}{lccc}
\hline \multicolumn{1}{c}{ Performed prophylaxis } & $\begin{array}{c}\text { Number } \\
\text { of infants }\end{array}$ & $\begin{array}{c}\text { Expenditures } \\
\text { (BGN) }\end{array}$ & $\begin{array}{c}\text { Expenditure } \\
\text { per one infant } \\
\text { (BGN) }\end{array}$ \\
\hline $\begin{array}{l}\text { Infants with corticosteroid } \\
\text { prophylaxis }\end{array}$ & 89 & 245827 & 2762,10 \\
$\begin{array}{l}\text { Infants without } \\
\text { corticosteroid prophylaxis }\end{array}$ & 72 & 269082 & 3737,25 \\
\begin{tabular}{l} 
Total (6 system error) \\
\hline
\end{tabular} & 161 & 514855 & 3197,85 \\
\hline
\end{tabular}

Table 2. Expenditures by CP for infants with complete and incomplete corticosteroid course.

\begin{tabular}{lcccc}
\hline $\begin{array}{c}\text { Type of } \\
\text { corticosteroid } \\
\text { course }\end{array}$ & $\begin{array}{c}\text { Applications } \\
\text { number }\end{array}$ & $\begin{array}{c}\text { Number } \\
\text { of infants }\end{array}$ & $\begin{array}{c}\text { Expenditures } \\
\text { (BGN) }\end{array}$ & $\begin{array}{c}\text { Expenditure } \\
\text { per one } \\
\text { infant } \\
\text { (BGN) }\end{array}$ \\
\hline Incomplete & 1 & 45 & 91068 & 2024 \\
Complete & 2 & 22 & 73100 & 3323 \\
Complete & 3 & 21 & 81197 & 3691 \\
\hline
\end{tabular}


effect on RDS than two or three corticosteroid applications (long-term preventive course). This conclusion is confirmed also by the analysis of the expenses made by clinical paths for infants with single application of Dexamethasone (incomplete preventive course) (Table 2 ). The expenditures made for this group are by almost $40 \%$ lower than those for infants with two or three Dexamethasone applications.

It can be generalized that the smaller number of Dexamethasone applications, besides the better preventive effect is also beneficial as demanding lower costs for further preterm infants' treatment and care.

\section{References}

Ballard RA, Truog WE, Cnaan A, et al. (2006) Inhaled Nitric Oxide in Preterm Infants Undergoing Mechanical Ventilation. New England Journal of Medicine. July 2006. 355: 343353.

Blencowe H, Cousens S, Oestergaard M, Chou D, Moller AB, et al. (2012) National, regional and worldwide estimates of preterm birth rates in the year 2010 with time trends since 1990 for selected countries: a systematic analyses and implications. Lancet 379(9832): 2162-72. https://doi.org/10.1016/S0140-6736(12)60820-4

Brazilian Ministry of Health (2013) SINASC - National Information System on Live Births, 2013 Nov 27.

Carmichael SL, Abrams B (1997) A critical review of the relationship between gestational weight gain and preterm delivery. Obstetrics and Gynecology 89: 865-873. https://doi.org/10.1016/S00297844(97)00047-1

Chaikind S, Corman H (1991) The impact of low birthweight on special education costs. Journal of Health Economics 10: 291-311. https:// doi.org/10.1016/0167-6296(91)90031-H

Chan GJ, Lee ACC, Baqui AH, Tan J, Black RE (2013) „Risk of Early-Onset Neonatal Infection with Maternal Infection or Colonization: A Global Systematic Review and Meta-Analysis“. PLoS Medicine10(8): e1001502. https://doi.org/10.1371/journal.pmed.1001502

Arora CP, Kacerovsky M, Zinner B, Ertl T, Ceausu Iu, Rusnak I, Shurpyak S, Sandhu M, Hobel CJ, Dumesic DA, Vari SG (2015) RECOOP for Common Mechanisms of Diseases. „Disparities and relative risk ratio of preterm birth in six Central and Eastern European Centers". Croatian Medical Journal 56: 119-27. https://doi.org/10.3325/ cmj.2015.56.119

Chien LY, Ohisson A, Seshia MMK, Boulton J (2002) Variations in antenatl corticosteroid therapy: a persistent problem despite 30 years of evidence. Obstetrics \& Gynecology 99: 401-408. https://doi. org/10.1016/S0029-7844(01)01732-X

Crowley P (1995): Antenatal corticosteroid therapy: A meta-analysis of the randomized trials 1972-1984. American Journal of Obstetrics and Gynecology 173: 322-335. https://doi.org/10.1016/00029378(95)90222-8

Crowther CA, McKinlay CJD, Middleton P, Harding JE (2011) Repeat doses of prenatal corticosteroids for women at risk of prenatal birth for improving neonatal health outcomes. Cocrane Database Syst Rev; CD003935. https://doi.org/10.1002/14651858.CD003935.pub3

Danesh A, Janghorbani M, Khalatbari S (2012) Effects of antenatal corticosteroids on maternal serum indicators of infection in women at

\section{Conclusions}

Prenatal corticosteroids in preterm born infants cause reduction of the expenses allocated for their treatment.

The administration of a smaller number of dexamethasone applications also causes lower expenses for further treatment and care for premature infants than those for infants with a greater number of dexamethasone applications. A single prenatal administration of dexamethasone (defined as a short-term prophylactic course or incomplete course) has a better prophylactic effect on RDS than 2 or 3 corticosteroid applications (a long-term prophylactic course or complete course).

risk for preterm delivery: A randomized trial comparing betamethasone and dexamethasone. Journal of Research in Medical Science 17: 911-7.

Elimian A, Figureoa R, Spitzer AR, et al. (2003) Antenatal corticosteroids: are incomplete courses beneficial? Obstetrics \& Gynecology 102: 352-355. https://doi.org/10.1016/S0029-7844(03)00485-X

EURO-PERISTAT (2010) Project, with SCPE, EUROCAT, EURONEOAT. European Perinatal Health Report. [Accessed: April 1, 2015]

Fanaroff AA, Stoll BJ, Wright LL, et al. (2007) Trends in Neonatal Morbidity and Mortality for Very Low Birthweight Infants. American Journal of Obstetrics and Gynecology. February 2007. 147: e1-e8. https://doi.org/10.1016/j.ajog.2006.09.014

French NP, Hagan R, Evans SF, at al. (1999) Reoeated antenatal corticosteroids: size at birth and subsequent development. American Journal of Obstetrics and Gynecology 180: 114-121. https://doi.org/10.1016/ S0002-9378(99)70160-2

Goldenberg RL, Culhane JF, Iams JD, Romero R (2008) „Epidemiology and causes of preterm birth“. The Lancet 371 (9606): 75-84. https:// doi.org/10.1016/S0140-6736(08)60074-4

Hamilton BE, Martin JA, Ventura SJ (2011) Births: Preliminary data for 2010. National Vital Statistics Reports 62(1): 1-70.

Heaman M, Blanchard J, Gupton A, Moffatt M, Currie R (2005) Paediatric and Perinatal Epidemiology,19, Risk factors for spontaneous preterm birth among Aboriginal and nonAboriginal women in Manitoba, 181-193. https://doi.org/10.1111/j.1365-3016.2005.00644.x

Heron M (2012), Deaths: leading causes for 2008. National Vital Statistics Reports 60(6): 1-94. http://humrep.oxfordjournals.org/content/14/11/2891.full

Howson CP, Kinney MV, Lawn JE (2012) Born too soon: The global action report on preterm birth. Written report World Health Organization: Geneva.

Iams JD, Romero R, Culhane JF, et al. (2008) Primary, secondary, and tertiary interventions to reduce the morbidity and mortality of preterm birth. The Lancet 371: 164-75. https://doi.org/10.1016/ S0140-6736(08)60108-7

Krueger PM, Scholl TO (2000) Adequacy of prenatal care and pregnancy outcome. Journal of the American Osteopathic Association 100: 485-492.

Martin J, Hamilton B, Ventura S, Osterman M, Wilson E, Mathews T (2012) Births: final data for 2010. National Vital Statistics Reports 2012 61(1): 1-72. 
Drake RL, Vogl W, Mitchell AWM (2014) Gray's anatomy for students ( $3^{\text {rd }}$ ed.). Edinburgh: Elsevier Churchill Lvgst, 167-174.

Moore KL, Persaud TVN (2002) The Developing Human: Clinically Oriented Embryology( $7^{\text {th }}$ ed.).

Mori R, Kusuda S, Fujimura M (2011) Antenatal corticosteroids promote survival of extremely preterm infants born at 22 to 23 weeks of gestation. Journal of Pediatrics 159: 110-114. https://doi.org/10.1016/j. jpeds.2010.12.039

Petrou S, Mehta Z, Hockley C, Cook-Mozaffari P, Henderson J, Goldacre M (2003) The impact of preterm birth on hospital inpatient admissions and costs during the first 5 years of life. Pediatrics 112: 1290-7. https://doi.org/10.1542/peds.112.6.1290

Petrou S, Sach T, Davidson L (2001) The long-term costs of preterm birth and low birth weight: results of a systematic review. Child: Care, Health and Development 27(2): 97-115. https://doi.org/10.1046/ j.1365-2214.2001.00203.x

Petrou S (2005) The economic consequences of preterm birth during the first 10 years of life. BJOG. 112: 10-5. https://doi.org/10.1111/j.1471 0528.2005.00577.x
Preterm Labor and Birth: Condition Information (2015) http://www. nichd.nih.gov [03/11/2014. Retrieved 7 March 2015]

Rodriguez RJ, Martin RJ, Fanaroff AA (2002) „Respiratory distress syndrome and its management“. In: Fanaroff AA, Martin RJ (Eds) Neonatal-perinatal medicine: diseases of the fetus and infant. St. Louis: Mosby, 1001-1011.

RCOG [Royal College of Obstetricians and Gynaecologists] (2010)Antenatal corticosteroids to reduce neonatal morbidity and mortality. London (UK): Royal College of Obstetricians and Gynaecologists (RCOG);

Sandeva M, Uchikova E, (2016) Frequency and Medical-Social Aspects of Preterm Birth. Journal of Obstetrics and Gynecology, 2, 27-33.

Sinha S (2012) Essential neonatal medicine. Chichester, West Sussex: John Wiley \& Sons. [Access provided by the University of Pittsburgh] Steer P (2005) „The epidemiology of preterm labour“. British Journal of Obstetrics \& Gynaecology 112 (Suppl 1): 1-3. https://doi. org/10.1111/j.1471-0528.2005.00575.x 